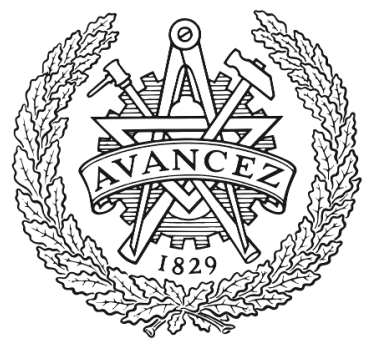

CHALMERS

UNIVERSITY OF TECHNOLOGY

\title{
Shining New Light on the Spiropyran Photoswitch: A Photocage Decides between cis-trans or Spiro-Merocyanine Isomerization
}

Downloaded from: https://research.chalmers.se, 2023-04-26 08:34 UTC

Citation for the original published paper (version of record):

Fleming, C., Li, S., Grötli, M. et al (2018). Shining New Light on the Spiropyran Photoswitch: A Photocage Decides between cis-trans or

Spiro-Merocyanine Isomerization. Journal of the American Chemical Society, 140(43): 14069-14072. http://dx.doi.org/10.1021/jacs.8b09523

N.B. When citing this work, cite the original published paper. 


\title{
Shining New Light on the Spiropyran Photoswitch: A Photocage Decides between cis-trans or Spiro-Merocyanine Isomerization
}

\author{
Cassandra L. Fleming, ${ }^{\dagger}$ Shiming Li, ${ }^{\ddagger}$ Morten Grøtli, ${ }^{\dagger}$ and Joakim Andréasson* ${ }^{*}$;(1) \\ ${ }^{\dagger}$ Department of Chemistry and Molecular Biology, University of Gothenburg, SE-41296 Göteborg, Sweden \\ ${ }^{\ddagger}$ Department of Chemistry and Chemical Engineering, Chemistry and Biochemistry, Chalmers University of Technology, SE-41296 \\ Göteborg, Sweden
}

Supporting Information

ABSTRACT: Photochromic molecules from the spiropyran family are known to undergo light-induced interconversion between the colorless spiro- and the colored merocyanine forms. Here, we show for the first time that small structural modifications open up for an additional photoisomerization mode: reversible cis-trans isomerization of the merocyanine. Moreover, the introduction of a photocage allows for light-activated switching between the two modes.

$\mathrm{P}$ hotochromic molecules, also referred to as molecular photoswitches, are used in a broad range of research disciplines. ${ }^{1-7}$ What started out as merely a curiosity (materials that change color upon light exposure) is today being explored in contexts such as optical data storage, ${ }^{1}$ light activated medicine, ${ }^{8,9}$ smart materials, ${ }^{6,7}$ and super resolution microscopy. ${ }^{10}$ Several classes of photochromic "backbones" are available for these purposes such as spiropyrans, azobenzenes, diarylethenes, and fulgimides. Moreover, these backbones can be decorated with various substituents to fit the intended use, adding to the diversity. Multiresponsive photochromic materials displaying more than one isomerization mode are indeed demonstrated, often realized by covalently linking two or more individual photoswitches. ${ }^{1-17}$ Typically, the main rationale in these studies has been to allow for selective switching between a multitude of isomeric states with distinct spectral features (e.g., color), potentially to be used for data storage beyond the binary notion or to mimic advanced logic operations. Other applications that may be of more immediate use rely not on the color change per se, but instead on the concomitant structural changes. Photopharmacology is a prime example in which photoactive molecules are designed to interact with the biomolecule of interest only after exposure to light, changing the structure from the passive form to the active form. ${ }^{8,9,18}$ Azobenzene derivatives (cis-trans isomerization) together with diarylethenes and spiropyrans (ring-opening/ closing) are frequently used in this context. ${ }^{19-23}$ Moreover, caged compounds equipped with a photolabile protecting group are identified as irreversibly activated alternatives. ${ }^{24,25}$ Here, we report on a molecular photocaged multiswitch that displays both cis-trans and spiro-merocyanine isomerization around one and the same photochromic backbone. The appended photocage is controlling which one of the two isomerization modes is active. Decaging implies dramatic changes in absorption and emission, in line with a release-andreport function. ${ }^{26}$ Interestingly, metastable cis-merocyanine isomers involved in reversible photoisomerization reactions are extremely rare, and the herein described example is only preceded by a rare-earth metal coordination complex or in the presence of strong acids such as triflic acid. ${ }^{27,28}$ Moreover, it constitutes the first report of a spiropyran with three different photoresponsive actions: cis-trans isomerization, photodecaging, and spiro-merocyanine isomerization.

Scheme 1 shows the structures and the interconversion pathways of compounds $\mathbf{1}$ and $\mathbf{2}$ used in this work. The asdissolved form of compound $\mathbf{1}$ is the caged trans-merocyanine 1c-trans-MC, as inferred from the NMR data in Figures S3 and S4 in the Supporting Information. The phenolate oxygen is equipped with a 2-nitrobenzyl photolabile caging group (photocage), which efficiently prevents ring-closing to the spiro-form. The synthesis is outlined in the Supporting Information. The absorption spectrum of this form in ethanol is shown in Figure 1 and displays the same spectral hallmark as 2Me-trans-MC and $\mathbf{1 M C H}$ presented herein (Scheme 1 and absorption spectra in Figures S14 and S15) as well as previously reported $\mathrm{MCH}$ derivatives: the longest wavelength absorption band centered at around $400 \mathrm{~nm} .^{29,30}$ This form displays excellent thermal stability, as no significant changes in the absorption spectrum are observed over 3 days in the dark.

Exposing 1c-trans-MC to $405 \mathrm{~nm}$ light results in virtually total disappearance of the absorption band at $400 \mathrm{~nm}$, showing that the photoreaction proceeds to almost complete formation of the photoproduct (Figure 1, green line). This band is fully recovered thermally with a time constant of $38 \mathrm{~min}$ at room temperature and recovered to $\sim 60 \%$ at the photostationary state with $302 \mathrm{~nm}$ light exposure (blue line). The thermal isomerization process has an activation energy of $16.3 \mathrm{kcal} /$ mol. The isomerizations proceed with an isosbestic "region" between $\sim 320$ and $335 \mathrm{~nm}$, indicating a clean conversion between the two implicated forms. This behavior is paralleled also by 2Me-trans-MC (Figure S14). Repeated photocycling with alternating 302 and $405 \mathrm{~nm}$ exposure was performed for five cycles without significant spectral deviations, other than a slow buildup of a band at around $541 \mathrm{~nm}$ and a corresponding decrease at around $300 \mathrm{~nm}$, as discussed below (see Figure S17). Figure 1 (magenta line) shows the absorption spectrum at thermal equilibrium subsequent to the five cycles.

Received: September 3, 2018

Published: October 15, 2018 
Scheme 1. Interconversion Pathways between Relevant Forms of Photoswitches 1 and $2^{a}$

a
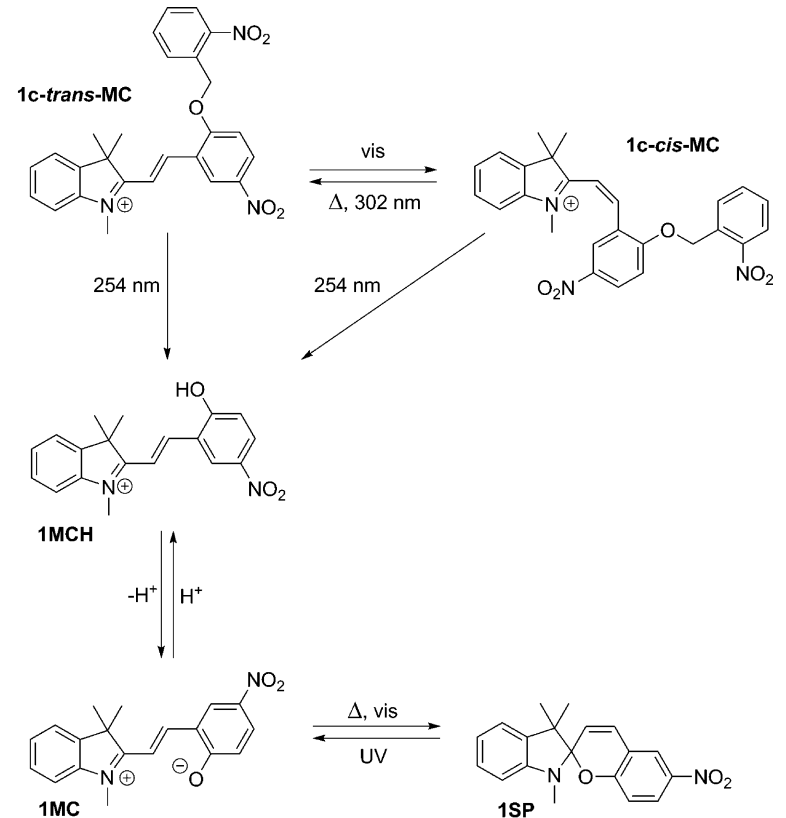

b

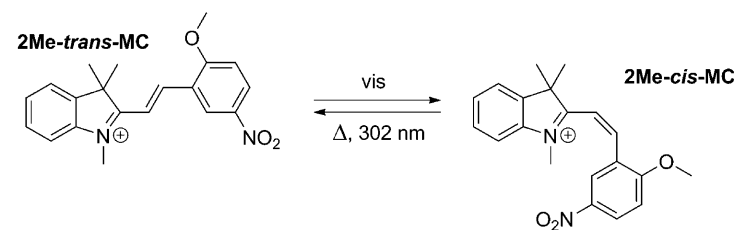

${ }^{a}$ Compound $\mathbf{1}$ is equipped with a photolabile caging group (photocage) at the phenolate oxygen (a), whereas $\mathbf{2}$ has a photostable methyl group in the same position (b). Please note that all cis-isomers are arbitrarily indicated in the CCT form rather than the corresponding CCC (see Figure S12).

Spiro-merocyanine isomerization cannot be attributed the observed spectral changes as $405 \mathrm{~nm}$ light is outside the photoactive absorption spectrum of the photocage shown in Figure S16, and decaging is required for the formation of 1SP. Furthermore, the UV-vis absorption as well as the NMR spectral features are very different from that of 1SP (cf Figures S15, S20, and S23). From the NMR studies shown in Figure 2, it is seen that the coupling constant of the vinylic protons $\mathrm{H}-10$ and $\mathrm{H}-11$ of $1 \mathrm{c}$-trans-MC is $16.8 \mathrm{~Hz}$. This is to be compared to the corresponding value of $12.8 \mathrm{~Hz}$ after exposure to 405 $\mathrm{nm}$ light, which is consistent with a cis-trans isomerization of 1c-trans-MC to yield 1c-cis-MC according to Scheme $1 .^{27,28}$ It should be noted that structurally similar merocyanine derivatives carrying alkylated phenolate oxygens have been reported before, but none of these studies investigated photoinduced cis-trans isomerizations. ${ }^{31-34}$

The corresponding values for the methylated derivative $\mathbf{2}$ are 16.4 and $13.2 \mathrm{~Hz}$ for trans- and cis-isomers, respectively, further supporting this notion. ${ }^{35}$ Moreover, we would like to stress the similarities between the absorption spectra observed after 405 $\mathrm{nm}$ exposure and the spectra frequently ascribed to a protonated cis-merocyanine observed under very acidic conditions, often in cavitand hosts. ${ }^{28,36-39}$ Similar assignments have been made for merocyanine isomers complexed to metal ions, albeit with slightly different spectral positions. ${ }^{27,40}$ It should be emphasized, however, that with two exceptions

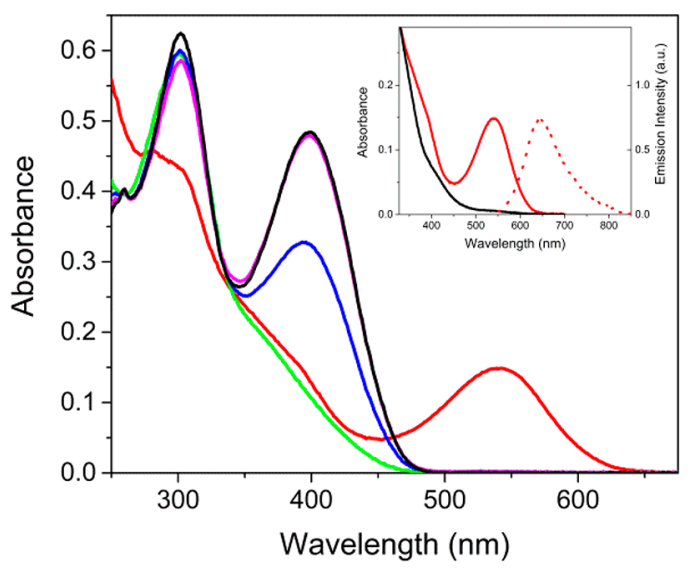

Figure 1. Absorption spectra of 1c-trans-MC before irradiation (black line) and after irradiation at $405 \mathrm{~nm}$ to generate 1c-cis-MC (green line). Subsequent irradiation at $302 \mathrm{~nm}$ yields a photostationary distribution (PSD) enriched to $\sim 60 \%$ of 1c-trans-MC (blue line). Exposure to five cycles of alternating 302 and $405 \mathrm{~nm}$ light yields the magenta line after thermal equilibrium establishment. Decaging with $254 \mathrm{~nm}$ UV results in the formation of $1 \mathrm{MC}$, evidenced by the absorption band at $541 \mathrm{~nm}$ (red line). Inset: Excitation into the 1MC band results in fluorescence emission centered at around $640 \mathrm{~nm}$ (dotted line) and eventual isomerization to the 1SP isomer (black line). All spectra in ethanol solution at a total concentration of $3.4 \times$ $10^{-5} \mathrm{M}$.
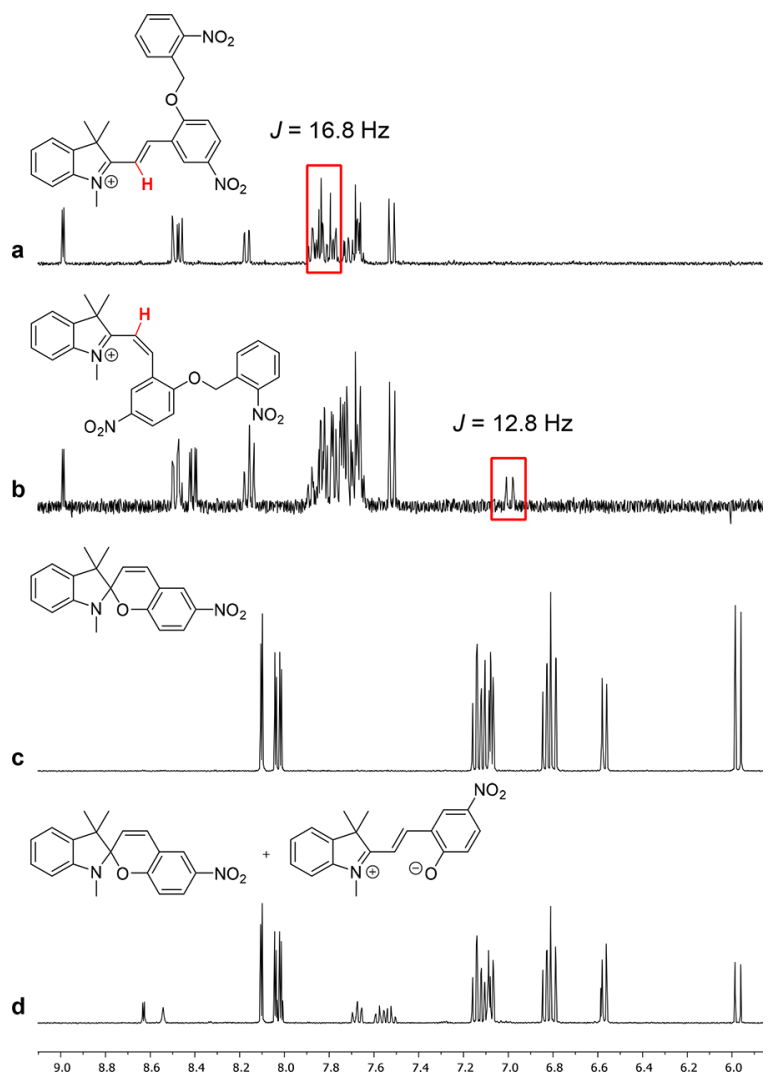

Figure 2. ${ }^{1} \mathrm{H}$ NMR spectra $\left(400 \mathrm{MHz}, \mathrm{CD}_{3} \mathrm{OD}\right)$ of compound 1 before (a) and after (b) exposure to visible light (see Table S1). ${ }^{1} \mathrm{H}$ NMR spectra $\left(400 \mathrm{MHz}, \mathrm{CD}_{3} \mathrm{OD}\right)$ of 1 SP before (c) and after (d) exposure to $365 \mathrm{~nm}$ for $30 \mathrm{~min}$ have also been included for comparison. 
implying complexation to rare-earth metals or the presence of strong acids, ${ }^{27,28}$ reversible photocycling between the cis- and the trans-merocyanine forms has not been demonstrated in any of the previous reports on spiropyran derived cis-merocyanines. This should be contrasted to the efficient and reversible cistrans isomerization observed herein for $\mathbf{1}$ and 2. Moreover, the process is occurring without the need for complex-formation or strong acids, dramatically increasing the application window.

If 1c-trans-MC is instead exposed to $254 \mathrm{~nm}$ light for $4 \mathrm{~min}$, the spectral changes include a decrease in the band at $400 \mathrm{~nm}$ together with the appearance of a new band at around $541 \mathrm{~nm}$. The band at $541 \mathrm{~nm}$ is easily recognized as belonging to the merocyanine form of 6-nitroBIPS (1MC in Scheme 1 and Figure S15), as it is identical to that of "as synthesized" $\mathbf{1 S P}$ after UV irradiation to yield 1 MC. ${ }^{41}$ This shows that $254 \mathrm{~nm}$ light indeed is triggering the decaging of the 2-nitrobenzyl group from the phenolate oxygen of $1 \mathrm{c}-$ trans-MC, as expected from the absorption spectrum of the model photocage cmodel alone shown in Figure S16. Although the light at 302 $\mathrm{nm}$ used to stimulate the $\mathbf{1 c}$-cis-MC $\rightarrow \mathbf{1 c}$-trans-MC isomerization is within the absorption spectrum of the photocage, decaging is $\sim 100$-times slower than the highly efficient cis $\rightarrow$ trans isomerization using this wavelength (an isomerization quantum yield of 0.82 is reported for a structurally very similar derivative). ${ }^{28,42}$ Thus, the cis $\rightarrow$ trans photoisomerization induced by $302 \mathrm{~nm}$ light described above occurs freely without any significant contribution from decaging.

Exposure to $254 \mathrm{~nm}$ UV light not only decages 1c-transMC/1c-cis-MC to yield $\mathbf{1 M C}$, but it also isomerizes $1 \mathrm{MC}$ to 1SP to yield a photostationary distribution (PSD) fairly low with respect to $1 \mathrm{MC}$. Moreover, in the decaging mechanism shown in Figure S19 protonation of 1MC may result to yield $1 \mathrm{MCH}$. Indeed, adding $1 \mu \mathrm{L}$ of triethylamine to the solution, followed by exposure to $302 \mathrm{~nm}$, results in an increased absorption at $541 \mathrm{~nm}$, which levels out at a value corresponding to a PSD consisting of $\sim 1 / 3$ 1MC (Figure 1, red line). When left in the dark, the sample reverts almost quantitatively to $\mathbf{1 S P}$ with a time constant of $28 \mathrm{~min}$ or faster upon exposure to visible light, here at $523 \mathrm{~nm}$. Figure S18 shows the results from extended photocycling of this isomerization mode performed for 10 cycles. Judging from the absorption band of $1 \mathrm{MC}$ at $541 \mathrm{~nm}$, the cycling occurs without significant spectral perturbations other than the buildup of a visible-light absorbing species with time. The spectral evolution at shorter wavelength, however, clearly indicates residual cis-trans isomerization implying that the preceding decaging step did not go to completion. ${ }^{3}$

In addition to the distinguishing absorption band at $541 \mathrm{~nm}$, 1MC displays characteristic fluorescence centered at around $640 \mathrm{~nm}$, with a quantum yield of $0.012 .{ }^{44}$ The emission spectrum is shown in the inset of Figure 1. Hence, there are two spectral features unique for $\mathbf{1 M C}$, both of which can be used to report back that decaging has occurred and that spiromerocyanine isomerization is now the active mode. This feature is often referred to as release-and-report, typically in a context where a decaged, or activated, compound has characteristic spectral features which signal that activation did occur. ${ }^{26}$

Although the results from this study must be regarded as a proof-of-principle, we anticipate that the herein applied scheme could be of relevance in chemical biology. As described above, cis-trans isomerizations are key to many lightcontrolled interactions between small molecules, such as azobenzene derivatives, and their biological targets. This is true also for the ring-closing/opening involved in the isomerization reactions for diarylethenes and spiropyrans. Combining these isomerization modes in one and the same structure allows for a multitude of molecular geometries to be adopted using light as an externally controlled trigger. This is highly desired when it comes to increasing the difference in affinity to the biological target before and after light exposure.

In conclusion, we have designed a spiropyran-based photoswitch displaying three distinct photoresponsive actions: cis-trans isomerization around the merocyanine vinylic double bond, photodecaging of a 2-nitrobenzyl group at the phenolate oxygen, and isomerization between the spiro- and the merocyanine isomer. Decaging not only controls which one of the two isomerization modes is activated, but also it induces dramatic changes in both absorption and emission, which implies an inherent release-and-report function. We anticipate that the overall isomerization scheme presented could help to target interactions with biorelevant molecules, which would be of great generic value in, for example, photopharmacological contexts.

\section{ASSOCIATED CONTENT}

\section{S Supporting Information}

The Supporting Information is available free of charge on the ACS Publications website at DOI: 10.1021/jacs.8b09523.

Synthetic procedures, NMR spectra, UV-vis absorption spectra of model compounds, photocycling, decaging mechanism (PDF)

\section{AUTHOR INFORMATION}

\section{Corresponding Author}

*a-son@chalmers.se

ORCID $\odot$

Cassandra L. Fleming: 0000-0002-7730-7305

Morten Grøtli: 0000-0003-3621-4222

Joakim Andréasson: 0000-0003-4695-7943

\section{Notes}

The authors declare no competing financial interest.

\section{ACKNOWLEDGMENTS}

This project received funding from the European Union's Horizon 2020 research and innovation programme under Grant Agreement No. 745626. J.A. acknowledges the Swedish Research Council for funding (VR Grant No. 2016-03601).

\section{REFERENCES}

(1) Irie, M. Thematic Issue on Photochromism: Memories and Switches. Chem. Rev. 2000, 100, 1683-1890.

(2) Brieke, C.; Rohrbach, F.; Gottschalk, A.; Mayer, G.; Heckel, A. Angew. Chem., Int. Ed. 2012, 51, 8446-8476.

(3) Göstl, R.; Senf, A.; Hecht, S. Chem. Soc. Rev. 2014, 43, 19821996.

(4) Gust, D.; Andréasson, J.; Pischel, U.; Moore, T. A.; Moore, A. L. Chem. Commun. 2012, 48, 1947-1957.

(5) Szymanski, W.; Beierle, J. M.; Kistemaker, H. A. V.; Velema, W. A.; Feringa, B. L. Chem. Rev. 2013, 113, 6114-6178.

(6) Wang, L.; Li, Q. Chem. Soc. Rev. 2018, 47, 1044-1097.

(7) Zhang, J. J.; Wang, J. X.; Tian, H. Mater. Horiz. 2014, 1, 169184.

(8) Broichhagen, J.; Frank, J. A.; Trauner, D. Acc. Chem. Res. 2015, 48, 1947-1960. 
(9) Lerch, M. M.; Hansen, M. J.; van Dam, G. M.; Szymanski, W.; Feringa, B. L. Angew. Chem., Int. Ed. 2016, 55, 10978-10999.

(10) Roubinet, B.; Weber, M.; Shojaei, H.; Bates, M.; Bossi, M. L.; Belov, V. N.; Irie, M.; Hell, S. W. J. Am. Chem. Soc. 2017, 139, 66116620.

(11) Bälter, M.; Li, S. M.; Nilsson, J. R.; Andréasson, J.; Pischel, U. J. Am. Chem. Soc. 2013, 135, 10230-10233.

(12) Fihey, A.; Perrier, A.; Browne, W. R.; Jacquemin, D. Chem. Soc. Rev. 2015, 44, 3719-3759.

(13) Higashiguchi, K.; Matsuda, K.; Tanifuji, N.; Irie, M. J. Am. Chem. Soc. 2005, 127, 8922-8923.

(14) Szaloki, G.; Sevez, G.; Berthet, J.; Pozzo, J. L.; Delbaere, S. J. Am. Chem. Soc. 2014, 136, 13510-13513.

(15) Vlasceanu, A.; Koerstz, M.; Skov, A. B.; Mikkelsen, K. V.; Brøndsted Nielsen, M. Angew. Chem., Int. Ed. 2018, 57, 6069-6072.

(16) Yonekawa, I.; Mutoh, K.; Kobayashi, Y.; Abe, J. J. Am. Chem. Soc. 2018, 140, 1091-1097.

(17) Lerch, M. M.; Hansen, M. J.; Velema, W. A.; Szymanski, W.; Feringa, B. L. Nat. Commun. 2016, 7, 12054.

(18) Velema, W. A.; Szymanski, W.; Feringa, B. L. J. Am. Chem. Soc. 2014, 136, 2178-2191.

(19) Andersson, J.; Li, S. M.; Lincoln, P.; Andréasson, J. J. Am. Chem. Soc. 2008, 130, 11836-11837.

(20) Beharry, A. A.; Woolley, G. A. Chem. Soc. Rev. 2011, 40, 44224437.

(21) Vomasta, D.; Högner, C.; Branda, N. R.; König, B. Angew. Chem., Int. Ed. 2008, 47, 7644-7647.

(22) Young, D. D.; Deiters, A. ChemBioChem 2008, 9, 1225-1228.

(23) Silvi, S.; Constable, E. C.; Housecroft, C. E.; Beves, J. E.; Dunphy, E. L.; Tomasulo, M.; Raymo, F. M.; Credi, A. Chem. Commun. 2009, 1484-1486.

(24) Mayer, G.; Heckel, A. Angew. Chem., Int. Ed. 2006, 45, 49004921.

(25) Bao, C. Y.; Zhu, L. Y.; Lin, Q. N.; Tian, H. Adv. Mater. 2015, 27, 1647-1662.

(26) Wu, T. Q.; Tang, H.; Bohne, C.; Branda, N. R. Angew. Chem., Int. Ed. 2012, 51, 2741-2744.

(27) Selvanathan, P.; Dorcet, V.; Roisnel, T.; Bernot, K.; Huang, G.; Le Guennic, B.; Norel, L.; Rigaut, S. Dalton Trans 2018, 47, 41394148.

(28) Kortekaas, L.; Chen, J.; Jacquemin, D.; Browne, W. R. J. Phys. Chem. B 2018, 122, 6423-6430.

(29) Raymo, F. M.; Giordani, S.; White, A. J. P.; Williams, D. J. J. Org. Chem. 2003, 68, 4158-4169.

(30) Remon, P.; Hammarson, M.; Li, S. M.; Kahnt, A.; Pischel, U.; Andréasson, J. Chem. - Eur. J. 2011, 17, 6492-6500.

(31) Promchat, A.; Rashatasakhon, P.; Sukwattanasinitt, M. J. Hazard. Mater. 2017, 329, 255-261.

(32) Yu, H.; Wu, Y. N.; Hu, Y.; Gao, X. D.; Liang, Q.; Xu, J.; Shao, S. J. Talanta 2017, 165, 625-631.

(33) Inouye, M.; Ueno, M.; Tsuchiya, K.; Nakayama, N.; Konishi, T.; Kitao, T. J. Org. Chem. 1992, 57, 5377-5383.

(34) Liu, C.; Lu, Y.; He, S.; Wang, Q.; Zhao, L. C.; Zeng, X. S. J. Mater. Chem. C 2013, 1, 4770-4778.

(35) In addition to the coupling constant of around $13 \mathrm{~Hz}$ for the vinylic protons $(\mathrm{H}-10$ and $\mathrm{H}-11)$ of the cis-isomers, long-range coupling between the $\mathrm{N}-\mathrm{CH}_{3}$ and $\mathrm{H}-10$ is also observed $(J=1.2 \mathrm{~Hz})$. This long-range coupling is observed also for 3Me-cis-MC (Figure S22). Furthermore, the same long-range coupling is found for compound SPMe-6H-cis-MCH previously reported in the literature (see Figure S26 and ref 28).

(36) Miskolczy, Z.; Biczok, L. J. Phys. Chem. B 2011, 115, 1257712583 .

(37) Miskolczy, Z.; Biczok, L. J. Phys. Chem. B 2013, 117, 648-653.

(38) Drummond, C. J.; Furlong, D. N. J. Chem. Soc., Faraday Trans. 1990, 86, 3613-3621.

(39) Zhou, J. W.; Li, Y. T.; Tang, Y. W.; Zhao, F. Q.; Song, X. Q.; Li, E. C. J. Photochem. Photobiol., A 1995, 90, 117-123.
(40) Wojtyk, J. T. C.; Kazmaier, P. M.; Buncel, E. Chem. Mater. 2001, 13, 2547-2551.

(41) Klajn, R. Chem. Soc. Rev. 2014, 43, 148-184.

(42) The factor $\sim 100$ difference between the rate of isomerization and the rate of decaging was experimentally obtained by comparing the kinetics of the cis $\rightarrow$ trans isomerization in compound $\mathbf{1}$ to that of the decaging of c-model using identical irradiation conditions with $302 \mathrm{~nm}$ UV light.

(43) The "apparent" absence of $\mathbf{1 M C}$ decomposition throughout the MC-SP cycling is explained by decaging (to form additional $\mathbf{1 M C}$ isomer) throughout the cycling.

(44) Chibisov, A. K.; Görner, H. J. Phys. Chem. A 1997, 101, 43054312. 